\title{
Effects of DJ-7141, a New Peripherally Acting Alpha-2 Adrenoceptor Agonist, on Blood Pressure and Gastric Acid Output in Rats: Evidence for the Heterogeneity of Alpha-2 Adrenoceptors in Different Organs
}

\author{
Kunihiko YOKOTANI and Yoshitsugu OSUMI \\ Department of Pharmacology. Kochi Medical School. Nankoku. Kochi $781-51$, Japan
}

Accepted January 9, 1987

\begin{abstract}
Effects of intravenously administered clonidine and DJ-7141 on blood pressure and gastric acid output were studied in anesthetized rats. Both drugs caused a dose-dependent increase in blood pressure. Clonidine-induced increases in the blood pressure were attenuated by yohimbine and prazosin. DJ-7141induced increases in blood pressure were also attenuated by yohimbine, but were little affected even by a large dose of prazosin. Splanchnic nerve stimulationinduced increases in blood pressure were attenuated by clonidine and DJ-7141. The inhibitory effects of DJ-7141 exceeded thase of clonidine. On the other hand, these agonists had no effect on exogenously applied norepinephrine-induced increases in blood pressure. Vagally stimulated gastric acid output was inhibited by small doses of clonidine and large doses of DJ-7141. Clonidine-induced inhibition of acid output was abolished by yohimbine $(5 \mathrm{mg} / \mathrm{kg})$, but not by prazosin ( $5 \mathrm{mg} / \mathrm{kg}$ ). In contrast, the DJ-7141-induced inhibition of acid output was not affected by yohimbine $(5 \mathrm{mg} / \mathrm{kg}$ ), but was attenuated by a small dose of prazosin $(0.1 \mathrm{mg} / \mathrm{kg})$. These results indicate that DJ -7141 had no effect on alpha-2 adrenoceptors in gastric parasympathetic nerves. Furthermore, the alpha-2 adrenoceptors on parasympathetic nerves in the gastric wall are probably pharmacologically different from those on sympathetic nerves and blood vessels in rats.
\end{abstract}

Alpha adrenoceptors have been grouped into two subclasses $(1,2)$, originally based on anatomical considerations, alpha-1 for postsynaptic and alpha-2 for presynaptic alpha adrenoceptors. A simultaneous $O C^{-}$ currence of postsynaptic alpha-1 and 2 adrenoceptors was discovered in vascular smooth muscle (3). Thus, the term alpha-1 and alpha-2 adrenoceptors should be characterized from the pharmacological point of view $(4,5)$. Drugs exert various degrees of alpha-1/alpha- 2 selectivity, and clonidine revealed a relative selectivity for alpha-2 adrenoceptors, whereas methoxamine and phenylephrine exerted high selectivity for alpha-1 adrenoceptors (6-8). For adrenergic blocking drugs, prazosin revealed a high selectivity for alpha- 1 adrenoceptors (9) and yohimbine for alpha-2 adrenoceptors $(10,11)$.

In the present experiments, we found that an inhibition of rat gastric acid output induced by large doses of DJ-7141 (Fig. 1), a newly synthetized, peripherally acting alpha-2 adrenoceptor agonist (12), was antagonized by prazosin but not by yohimbine.

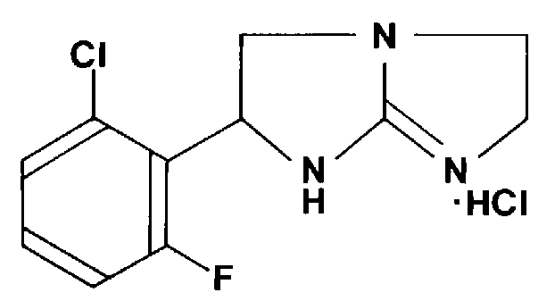

Fig. 1. Chemical structure of DJ-7141 [2-(2chloro-6-fluorophenyl) -2,3,5,6-tetrahydro-1 Himidazo (1.2-a) imidazolehydrochloride] 
Recently, there has been mounting evidence indicating the pharmacological heterogeneity of alpha-2 adrenoceptors. However, it is unclear whether presynaptic alpha- 2 adrenoceptors on the parasympathetic nerves share the same characteristics as those located pre- and postsynaptically on vascular sympathetic nervous systems. Therefore, the effects of clonidine and DJ-7141 on the alpha adrenoceptors in the pre- and postsynaptic vascular sympathetic nervous system and those in the gastric parasympathetic nervous system were studied in the urethaneanesthetized rats. Our observation suggests the heterogeneity of alpha-2 adrenoceptors in various rat organs.

\section{Materials and Methods}

Drug actions on the resting levels in blood pressure: Drug actions on the vascular postsynaptic alpha adrenoceptors of the sympathetic nervous system were determined by elevations in diastolic blood pressure. Male Wistar rats weighing 300$350 \mathrm{~g}$ were anesthetized with urethane (1.0 $\mathrm{g} / \mathrm{kg}$, i.p.), and atropine sulphate (1 $\mathrm{mg} / \mathrm{kg}$ ) and propranolol (5 $\mathrm{mg} / \mathrm{kg}$ ) were given intramuscularly. The blood pressure in the femoral artery was recorded. All test substances were injected into the femoral vein. The maximum increase in diastolic blood pressure $(\mathrm{mmHg})$ produced by each dose of clonidine or DJ-7141 was measured. The vasopressor-response curve to clonidine or DJ-7141 was obtained with a small dose of these drugs, then after $10-20 \mathrm{~min}$, with higher doses.

The effects of the alpha-adrenoceptor blocking agents yohimbine and prazosin on the vasopressor-response of clonidine or DJ7141 were tested in separate experiments: the cumulative doses of yohimbine or prazosin were intravenously (i.v.) injected 10 min before repeated injections of a fixed dose of the agonists $(5 \mu \mathrm{g} / \mathrm{kg}$ of clonidine and $100 \mu \mathrm{g} / \mathrm{kg}$ of DJ-7141).

Drug actions on increases in blood pressure induced by splanchnic nerve stimulation: Drug actions on the presynaptic alpha-adrenoceptors of the sympathetic nerves were determined by inhibition of the splanchnic nerve stimulation-induced in- crease in diastolic blood pressure. With the rats under urethane anesthesia, vagus nerves were cut bilaterally at the cervical portion. The right greater splanchnic nerve was approached retroperitoneally through a dorsal incision, and the adrenal branch was freed from the greater splanchnic nerve. The greater splanchnic nerve was cut just beneath the diaphragm, and the distal end was placed on platinum ring electrodes. Stimulus parameters were square-wave pulses of 2.0 msec duration, 0.5 to $5 \mathrm{~Hz}$, supramaximal intensity $(2.0 \mathrm{~mA})$, as described in our previous paper (13). Norepinephrine (NE) was injected through the femoral vein, in separate experiments. In both experiments. propranolol $(5 \mathrm{mg} / \mathrm{kg})$ was administered intramuscularily. Vasopressor-responses to splanchnic nerve stimulation or injection of NE were obtained before and after administration of cumulative doses of clonidine or DJ-7141. Fifteen min was allowed to elapse after each dose of agonist before splanchnic nerve stimulation or the injection of NE.

Drug actions on increases in gastric acid output induced by vagus nerve stimulation: Drug actions on the presynaptic alpha adrenoceptors of the parasympathetic nerves were determined by inhibition of vagally induced gastric acid output. With the rats under urethane anesthesia, vagus nerves were cut bilaterally at the cervical portion. The abdomen was opened by a midline incision, and a polyethylene cannula was inserted into the stomach through the duodenum. The stomach was washed out with saline and then filled with $2.0 \mathrm{ml}$ of gastric solution of the following composition: 1:5 ( $/ \mathrm{v})$ mixture of glycine and mannitol adjusted to $300 \mathrm{mOsmol}$ and $\mathrm{pH}$ 3.5 by addition of $0.1 \mathrm{~N} \mathrm{HCl}$, according to Blair et al. (14). This instilled solution was replaced with fresh solution every $15 \mathrm{~min}$. The gastric acid output was determined as follows: the total volume of gastric solution recovered from the stomach every $15 \mathrm{~min}$ and $2.0 \mathrm{ml}$ of gastric fresh solution $(\mathrm{pH} \mathrm{3.5)} \mathrm{was}$ titrated to $\mathrm{pH} 7.0$ with $0.01 \mathrm{~N} \mathrm{NaOH}$, using a $\mathrm{pH}$ meter and autoburette. Acid contents secreted for $15 \mathrm{~min}$ were calculated and expressed as $\mu \mathrm{Eq} / 15 \mathrm{~min}$. After stabilization of the basal acid output, the peripheral end 
of the left cervical vagus nerve placed on bipolar platinum electrodes was stimulated continuously during experiments. Stimulus parameters used were square-wave pulses of $0.5 \mathrm{msec}$ duration, at $3 \mathrm{~Hz}$, supramaximal intensity $(0.5 \mathrm{~mA})$. Such conditions were the same as those reported in our previous papers $(13,15)$. After reaching the increased steady level of the acid output, clonidine or DJ-7141 was intravenously infused for 30 min. Prazosin or yohimbine was intramuscularly administered 45 min before the start of the vagal stimulation.

Drugs used: DJ-7141 [2-(2-chloro-6-fluorophenyl) - 2,3,5,6, - tetrahydro - $1 \mathrm{H}$ - imidazo (1,2-a) imidazole-hydrochloride] was a generous gift from Daiichi Seiyaku Co. Ltd. Tokyo, Japan; clonidine hydrochloride was from Boehringer, Ingelheim, FRG: and prazosin hydrochloride was from TaitoPfizer Co.. Tokyo, Japan. The following drugs were obtained commercially: atropine sulfate (Merck Sharp and Dohme, West Point, PA), d/-propranolol hydrochloride and yohimbine hydrochloride (Nakarai Chemicals Co., Kyoto, Japan).

\section{Results}

Eifects of clonidine and DJ-7141 on the resting blood pressure: The mean resting blood pressure before injection of clonidine and DJ-7141 was systolic, $115.8 \pm 3.3$ and diastolic, $84.2 \pm 2.7 \mathrm{mmHg}(n=10)$. Intravenous injections of clonidine or DJ-7141 caused rapid. transient increases in the blood pressure. Clonidine (1 to $100 \mu \mathrm{g} / \mathrm{kg}$ ) caused dose-dependent increases in diastolic blood pressure; the maximum increases was obtained at $100 \mathrm{\mu g} / \mathrm{kg}$. DJ-7141 (10 to $1000 \mu \mathrm{g} / \mathrm{kg}$ ) also caused dose-dependent increases in diastolic blood pressure; the maximum increases were obtained at 1000 $\mu \mathrm{g} / \mathrm{kg}$ (Fig. 2). The doses increasing the diastolic blood pressure by about $30 \mathrm{mmHg}$ were $5 \mu \mathrm{g} / \mathrm{kg}$ for clonidine and $100 \mu \mathrm{g} / \mathrm{kg}$ for DJ-7141, respectively. In the following experiments, these doses of agonists were used.

Cumulative administration of yohimbine (1 to $1000 \mu \mathrm{g} / \mathrm{kg}$ ) or prazosin (1 to 10000 $\mu \mathrm{g} / \mathrm{kg}$ ) from a small dose to larger doses sligtly decreased the resting blood pressor.

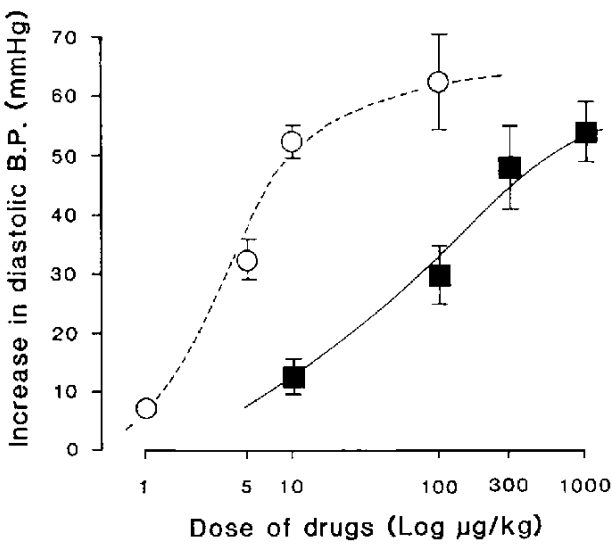

Fig. 2. Vasopressor responses to intravenous injection of clonidine (O) and DJ-7141 ( $(\mathbb{)}$ in anesthetized rats. Each point represents the increase in diastolic blood pressure (the mean \pm S.E. of five rats). The absolute values of the diastolic blood pressure before injection of agonists were $86.0 \pm 5.2$ $\mathrm{mmHg}$ for the clonidine-injected group and $82.4 \pm 1.9$ $\mathrm{mmHg}$ for the DJ-7141-injected group, respectively.

Clonidine $(5 \quad, \% \mathrm{~g} / \mathrm{kg}$ )-induced pressor responses were reduced by both yohimbine and prazosin in a dose-dependent manner (Fig. 3A, B). DJ-7141 (100 $\mu \mathrm{g} / \mathrm{kg})$-induced pressure responses were reduced by yohimbine (Fig. 3A), but little attenuated even by a large dose of prazosin (Fig. 3B). Each dose-inhibitory response curve was used for estimating the dose which inhibited the increase in blood pressure by $50 \%$ of the control value without antagonist (ID50). The mean ID50 values for yohimbine against clonidine and DJ-7141 were 502 and 284 $\mu \mathrm{g} / \mathrm{kg}$, respectively (Table 1 ). The mean ID50 value for prazosin against clonidine was $33.8 \mathrm{\mu g} / \mathrm{kg}$. but the value against DJ -7141 exceeded $10 \mathrm{mg} / \mathrm{kg}$. Therefore, 1050 yohimbine/ID50 prazosin ratio for DJ-7141 was much lower than the ratio for clonidine.

Effects of clonidine and DJ-7141 on the increase in blood pressure induced by splanchnic nerve stimulation or NE injection: Splanchnic nerve stimulation $(0.5$ to $5 \mathrm{~Hz}$ ) caused frequency-dependent increases in blood pressure, and at $3 \mathrm{~Hz}$, the increase in the diastolic pressure averaged about 30 $\mathrm{mmHg}$. Repetitive stimulation at $3 \mathrm{~Hz}$ for over ten times elicited a consistent and 

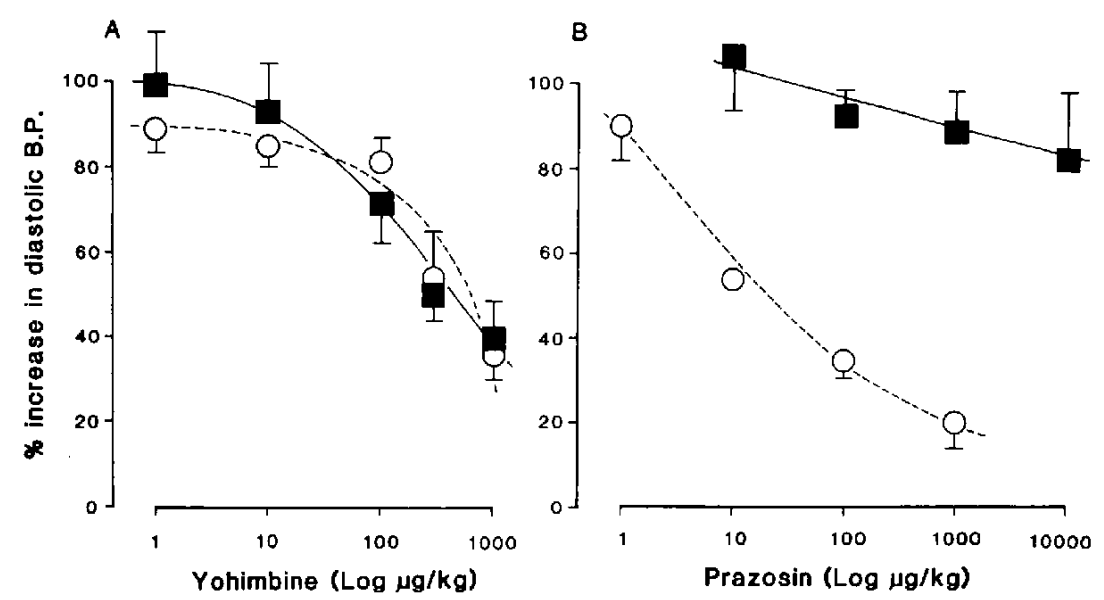

Fig. 3. The effects of yohimbine (A) and prazosin (B) on the vasopressor responses to intravenous injection of clonidine $(5 \mu \mathrm{g} / \mathrm{kg})(\mathrm{O})$ and DJ $-7141(100 \mu \mathrm{g} / \mathrm{kg})(\boldsymbol{D})$ in anesthetized rats. The effects of yohimbine and prazosin were expressed as a percent change of control values induced by clonidine or DJ-7141 alone. Each point represents the mean \pm S.E. of four rats. The absolute values of the increases in the diastolic blood pressure before administration of antagonists were $34.6 \pm 4.6 \mathrm{mmHg}$ for the clonidineadministered group $(n=8)$ and $27.4 \pm 2.1 \mathrm{mmHg}$ for the $D J-7141$-administered group $(n=8)$, respectively.

Table 1. Alpha-1/alpha-2 selectivity of clonidine and D.J-7141 in anesthetized rats

\begin{tabular}{|c|c|c|c|}
\hline \multirow{2}{*}{ Agonists } & \multicolumn{2}{|c|}{$1050^{a}$} & \multirow{2}{*}{$\begin{array}{l}Y^{b} \\
P\end{array}$} \\
\hline & Yohimbine $(Y)$ & Prazosin $(P)$ & \\
\hline $\begin{array}{l}\text { Clonidine } \\
\qquad(n=4)\end{array}$ & $\begin{array}{c}502 \\
(201-803)\end{array}$ & $\begin{array}{c}33.8 \\
(26.3-41.3)\end{array}$ & 14.9 \\
\hline $\begin{array}{r}\text { D. }-7141 \\
(n=4)\end{array}$ & $\begin{array}{c}284 \\
(187-381)\end{array}$ & $>10000$ & $<0.03$ \\
\hline
\end{tabular}

a D50 dose ( $\mu \mathrm{g} / \mathrm{kg}$, i.v.) of yohimbine and prazosin caused a $50 \%$ reduction in blood pressure increase induced by clonidine $(5 \mu \mathrm{g} / \mathrm{kg})$ and DJ-7141 $(100 \mu \mathrm{g} / \mathrm{kg})$. Results were expressed as the geometric mean (and $95 \%$ confidence limits). "The ratio 1050 yohimbine/ID50 prazosin was used as a measure of the alpha-1/alpha- 2 selectivity for the agonists tested.

reproducible increase in diastolic blood pressure. In further studies of the splanchnic nerve stimulation, a frequency of $3 \mathrm{~Hz}$ was used. Injection of NE $(0.1$ to $2 \mu \mathrm{g} / \mathrm{kg})$ also caused dose-dependent increases in the blood pressure: The increase in the diastolic blood pressure with $0.5 \mu \mathrm{g} / \mathrm{kg}$ of NE was all but equal to that induced by splanchnic nerve stimulation $(3 \mathrm{~Hz})$. Clonidine and DJ7141 reduced the increases in diastolic blood press:ure induced by splanchnic nerve stimulation. Ten $/ 2 \mathrm{~g} / \mathrm{kg}$ of clonidine and DJ-7141 decreased the diastolic blood pressure to $58.4 \%$ (41.6\% inhibition) and $49.8 \%$ (50.2\% inhibition) of the control values, respectively
(Fig. 4). Furthermore, the inhibition with $100 \mu \mathrm{gg} / \mathrm{kg}$ of DJ-7141 (54.5\% inhibition) was greater than that with the same dose of clonidine (39.7\% inhibition). On the other hand, neither clonidine nor DJ-7141 had any effect on the NE-induced increases in the diastolic blood pressure.

Effects of clonidine and DJ-7141 on the vagally stimulated gastric acid output: When the vagus nerve was continuously stimulated at $3 \mathrm{~Hz}$, the gastric acid output gradually increased and reached a steady level within 60 min, as noted earlier (13). This increased steady level was maintained for at least $2 \mathrm{hr}$ during continuous stimulation of the vagus 

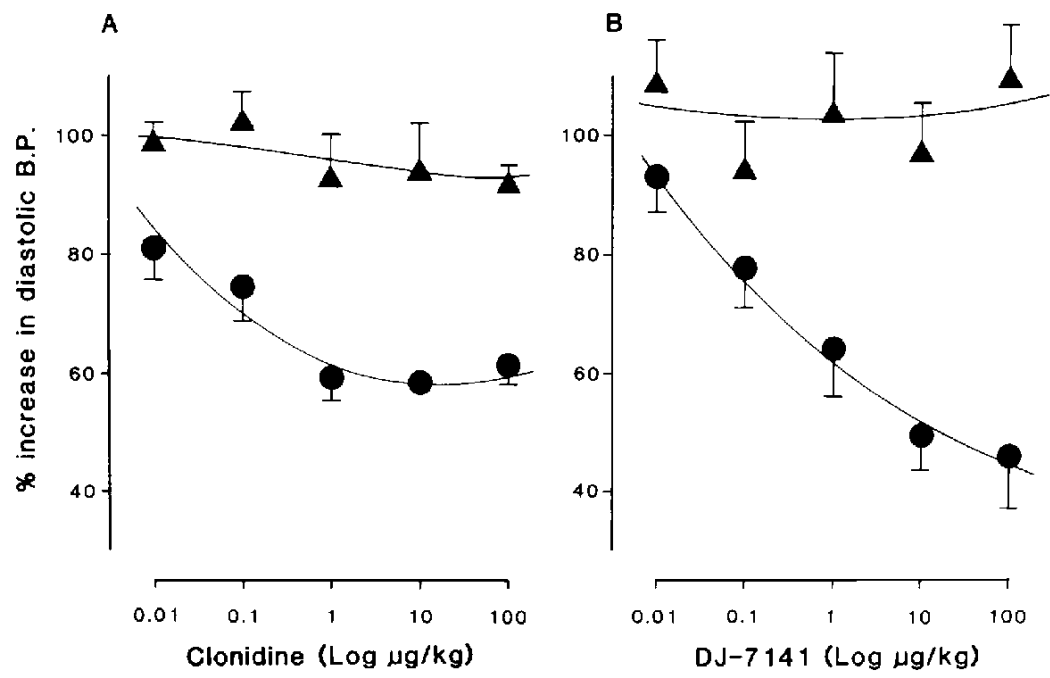

Fig. 4. The effects of clonidine (A) and DJ-7141 (B) on the vasopressor responses to stimulation of splanchnic nerve (O) and intravenous injection of norepinephrine (NE) ( $\boldsymbol{A})$ in anesthetized rats. Splanchnic nerve was stimulated by $3 \mathrm{~Hz}$, and norepinephrine was injected at $0.5 \mu \mathrm{g} / \mathrm{kg}$. The effects of clonidine and DJ-7141 were expressed as percent changes of control values induced by splanchnic nerve stimulation alone or infusion of NE alone. Each point represents the mean \pm S.E. of four rats. The absolute values of the increases in the diastolic blood pressure induced by splanchnic nerve stimulation and $\mathrm{NE}$ injection before administration of agonists were $30.0 \pm 1.9 \mathrm{mmHg}$ for splanchnic nerve-stimulated rats $(n=8)$ and $34.6 \pm 3.5 \mathrm{mmHg}$ for $\mathrm{NE}$-infused rats $(n=8)$.

nerve. Thus, infusion of clonidine and DJ7141 for $30 \mathrm{~min}$ was carried out $90 \mathrm{~min}$ after the beginning of vagal stimulation. Vagal stimulation-induced gastric acid secretion was abolished by atropine $(0.1$ $\mathrm{mg} / \mathrm{kg}, \mathrm{i} . \mathrm{v}$.).

Infusion of clonidine $(0.5$ and $2 \mu \mathrm{g} / \mathrm{kg} /$ $\mathrm{min}$ ) caused dose-dependent inhibitions on the vagally stimulated acid output. Furthermore, the inhibitory effects of clonidine on the acid output are abolished by yohimbine ( $5 \mathrm{mg} / \mathrm{kg}$ ), but are not influenced by prazosin $(5 \mathrm{mg} / \mathrm{kg}$ ). These findings already noted (15) were reconfirmed in the present study (data not shown)

Infusion of DJ-7141 (10 and $20 \mu \mathrm{g} / \mathrm{kg} /$ min) caused dose-dependent inhibitions: DJ-7141 $(10 \mu \mathrm{g} / \mathrm{kg} / \mathrm{min})$ decreased the acid output to $63.4 \%$ of the preinfused control values $(36.6 \%$ inhibition) at the third $15-\mathrm{min}$ collection period $(n=4)$ : DJ-7141 (20 $\mathrm{kg} /$ $\mathrm{kg} / \mathrm{min}$ ) decreased the acid output to $41.6 \%$ of the preinfused control values $(58.4 \%$ inhibition) at the third 15 -min collection period (Fig. 5A). These reductions in acid output persisted for over $45 \mathrm{~min}$. Inhibitory effects of DJ-7141 $(20 \mu \mathrm{g} / \mathrm{kg} / \mathrm{min})$ on the vagally stimulated acid output were not influenced by yohimbine $(5 \mathrm{mg} / \mathrm{kg})$ (Fig. $5 \mathrm{C}$ ). but were abolished by a small dose of prazosin (0.1 mg/kg) (Fig. 5B).

\section{Discussion}

In the present study, blood pressure in beta adrenoceptor-blocked rats was measured, since alpha-2 as well as alpha-1 adrenoceptors postsynaptically mediate pressor responses $(16,17)$. Clonidine and DJ - 7141 caused dose-dependent increases in blood pressure. Clonidine-induced increases in blood pressure were attenuated by yohimbine and prazosin in a dosedependent manner. DJ-7141-induced increases in blood oressure also were attenuated by yohimbine, but not by even large doses of prazosin. The ratio of the potencies of these drugs (ID50 yohimbine/ ID50 prazosin) required for antagonization was used as a measurement of the agonist's alpha-1/alpha-2 selectivity. Kobinger and 
Pichler (18) used the ratio D10 rauwolscine/ D10 prazosin for the measurement of the agonist's alpha-1/alpha- 2 selectivity, whereas D10 for the dose of antagonist which shifts

$\frac{\text { Vagal stimulation }}{\text { DJ-7141 }(20 \mu \mathrm{g} / \mathrm{kg} / \mathrm{min})}$

A: control
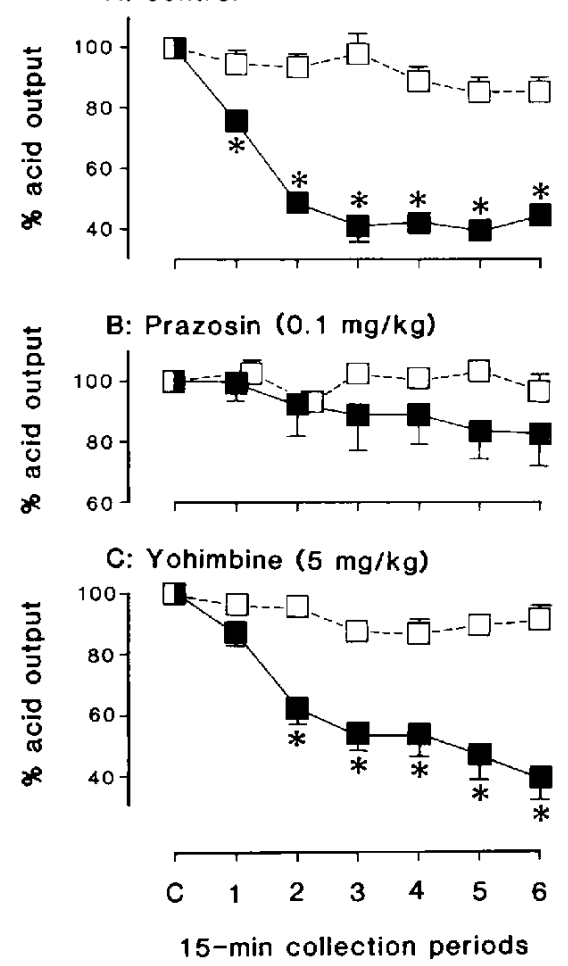

Fig. 5. Effects of prazosin and yohimbine on the DJ-7141-induced inhibition of the vagally stimulated gastric acid output. Ninety minutes after the start of stimulation of the vagus nerve $(3 \mathrm{~Hz}, 0.5 \mathrm{~mA}$, 0.5 msec duration). DJ $7141(20 \mu \mathrm{g} / \mathrm{kg} / \mathrm{min})$ was infused i.v. for two consecutive 15-min collection periods. A, nontreated control group: B, prazosintreated group: $C$, yohimbine-treated group. $\square$. control rats: DJ-7141-infused rats. The effects of DJ-7141 were expressed as a percentage of the values of the preinfused control collection period. Each point represents the mean $\pm S$.E. of six rats. Statistical significance was compared with the values of corresponding control rats using Student's $t$-test for unpaired comparisons. ${ }^{*} P<0.05$. The absolute values of the control collection period (C) were $86.8 \pm 7.6 \mu \mathrm{Eq} / 15 \mathrm{~min}$ in group $\mathrm{A}(\mathrm{n}=12): 72.4 \pm 8.6$ $\mu \mathrm{Eq} / 15 \mathrm{~min}$ in group $\mathrm{B}(\mathrm{n}=12) ; 87.7 \pm 8.1 \mu \mathrm{Eq} / 15$ $\min$ in group $C(n=12)$, respectively. the original dose-response curve ten-fold to the right. The ratio (D10 rauwolscine/D10 prazosin) 7.86 for clonidine in their study is not significantly different from the ratio (ID50 yohimbine/ID50 prazosin) 14.9 for clonidine in the present study. The ratio for DJ-7141 was much smaller than that for clonidine. Thus, DJ-7141 is a more selective alpha-2 adrenoceptor agonist than clonidine in the rat vascular system.

Alpha-2 adrenoceptors were originally defined in terms of their capacity to modulate norepinephrine (NE) release and were assumed to occur on presynaptic terminals. From superfused guinea pig vas deferens, Marshall et al. (19) demonstrated that clonidine inhibits the release of $\left[{ }^{3} \mathrm{H}\right] \mathrm{NE}$ as induced by electrical stimulation. Muramatsu et al. (12) demonstrated that DJ-7141 inhibited the twitch responses of rat vas deferens and that this inhibition was abolished by yohimbine. In the present experiments, clonidine and DJ-7141 dosedependently reduced the increases in the blood pressure induced by electrical stimulation of the splanchnic nerve, but had no effect on exogenously applied NE-induced increases in blood pressure. Thus, it is apparent that clonidine and DJ-7141 presynaptically act on sympathetic nerves and reduce the NE release from sympathetic nerve terminals. The potency of DJ-7141 on the sympathetic nerves exceeds that of clonidine.

Receptors with pharmacological properties of the presynaptic alpha adrenoceptors also occur outside sympathetic nerves, for example on parasympathetic nerves $(20,21)$ and on non-neural cell such as platelets (22). In the present experiments, clonidine inhibited the vagally stimulated gastric acid output, and this inhibition was blocked by yohimbine, as reported elsewhere (15). A large dose of DJ-7141 also inhibited the acid output, and this inhibition was abolished by prazosin, but not by yohimbine. Thus, it is apparent that the clonidine-induced inhibition is mediated through alpha- 2 adrenoceptors, while the DJ-7141-induced inhibition is mediated through alpha-1 adrenoceptors. In our previous papers (13, 15, 23-25), we suggested that the splanchnic 
nerve in rats acts on the parasympathetic nerves in the gastric wall through alpha-2 adrenoceptors and on the structures peripheral to the postganglionic parasympathetic nerve terminals in the gastric wall through alpha-1 adrenoceptors, reducing parasympathetically stimulated gastric acid secretion. Drew (20) demonstrated that clonidine caused a concentration-dependent inhibition of the twitch responses of guinea pig ileum. Thus, clonidine acts on the pre- and/or postganglionic parasympathetic nerves in the gastric wall, reducing the release of acetylcholine from parasympathetic nerve terminals $(26,27)$. In contrast, DJ-7141 probably acts on structures peripheral to the parasympathetic nerve terminals (alpha-1 adrenoceptors), only when its large dose was applied, and reduces the vagally stimulated gastric acid secretion. From these results, it is apparent that DJ-7141 is unable to act on alpha-2 adrenoceptors located on the parasympathetic nerves in the gastric wall. In addition, the alpha-1 adrenoceptor agonistic activity of this agent is probably very weak.

There is mounting evidence indicating the pharmacological heterogeneity of alpha2 adrenoceptors. From $\left[{ }^{3} \mathrm{H}\right]$ yohimbine-and $\left[{ }^{3} \mathrm{H}\right]$ oxymethazoline-binding studies on the human caudate nucleus. Petrash and Bylund (28) showed that prazosin inhibition curves for both ligands were consistent with two classes of binding sites, suggesting that this tissue contains two types of alpha- 2 adrenoceptors: one has a lower affinity for prazosin (alpha-2A), another has a high affinity for prazosin (alpha-2B). Alpha-2B adrenoceptors are not alpha-1 adrenoceptors since the affinity of prazosin for the alpha- 1 adrenoceptors is 240 -fold greater than it is at the alpha-2B adrenoceptors. However. no consideration as to localization of these adrenoceptors was included. Tsukahara et al. (29) demonstrated that dog cerebral arteries have two binding sites of $\left[{ }^{3} \mathrm{H}\right]$ yohimbine (high and low affinity binding sites), and sympathectomy led to the loss of the high affinity binding sites. In our present experiments, we confirmed two types of alpha-2 adrenoceptors in vivo; one is sensitive to DJ-7141, another is insensitive to DJ-7141 and locates on the parasympathetic nerves in the gastric wall.

In conclusion, it was demonstrated that DJ-7141 has greater selective agonistic activities for pre- and postsynaptic alpha-2 adrenoceptors in the sympathovascular system, as compared to events seen with clonidine. Furthermore, it is interesting to note that DJ-7141 has no agonistic activity for alpha-2 adrenoceptors located in the gastric parasympathetic nerves. From these results, it is suggested that a heterogeneity of alpha-2 adrenoceptors probably exists in different organs in rats.

Acknowledgement: We thank M. Ohara for comments on the manuscript.

\section{References}

1 Langer, S.Z.: Presynaptic regulation of catecholamine release. Biochem. Pharmacol. 23, 17931800 (1974)

2 Starke, K.: Regulation of noradrenaline release by presynaptic receptor systems. Rev. Physiol. Biochem. Pharmacol. 77, 1-124 (1977)

3 Jauernig, R.A., Moulds, R.F. and Shaw, J.: The action of prazosin in human vascular preparations. Arch. Int. Pharmacodyn. Ther. 231, 81-89 (1978)

4 Starke, K. and Langer, S.Z.: A note on terminology for presynaptic receptors. In Presyriaptic Receptors, Edited by Langer, S.Z., Starke, K. and Dubocovich, M.L., p. 1-3. Pergamon Press, Oxford (1979)

5 Langer, S.Z.: Presynaptic regulation of the release of catecholamines. Pharmacol. Rev. 32, 337-362 (1980)

6 Starke, K., Montel, H. Gayk, W. and Merker, R.: Comparison of the effects of clonidine on preand postsynaptic adrenoceptors in the rabbit pulmonary artery. Naunyn Schmiedebergs Arch. Pharmacol. 285, 133-150 (1974)

7 Berthelsen, S. and Pettinger, W.A.: A functional basis for classification of $\alpha$-adrenergic receptors. Life Sci. 21, 595--606 (1977)

8 Wikberg, J.E.S.: Pharmacological classification of adrenergic $\alpha$ receptors in the guinea pig. Nature 273, 164-166 (1978)

9 Cambridge, D., Davey, M.J. and Massingham, R.: Prazosin. a selective antagonist of postsynaptic $\alpha$-adrenoceptors. Br. J. Pharmacol. 59, 514P-515P (1977)

10 Starke, K., Borowski, E. and Endo, T.: Preferential blockade of presynaptic $\alpha$-adrenoceptors by yohimbine. Eur. J. Pharmacol. 34, 385- 
$388(1975)$

11 Weitzell, R., Tanaka, J. and Starke, K.: Pre- and postsynaptic effects of yohimbine stereoisomers on noradrenergic transmission in the pulmonary artery of the rabbit. Naunyn Schmiedebergs Arch. Pharmacol. 308, 127-136 (1979)

12 Muramatsu, I., Oshita, M., Hashimoto, S. and Kigoshi, S.: DJ-7141, a new alpha-2 agonist with only a mild hypotensive action. Japan. J. Pharmacol. 41, 61-68 (1986)

13 Yokotani, K., Muramatsu, I., Fujiwara, M. and Osumi, Y:: Effects of the sympathoadrenal system on the vagally induced gastric acid secretion and mucosal blood flow in rats. $J$. Pharmacol. Exp. Ther. 224, 436-442 (1983)

14 Blair, E.L., Grund, E.R., Reed, J.D., Sanders, D.J., Sanger, G. and Shaw, B.: The effect of sympathetic nerve stimulation on serum gastrin, gastric acid secretion and mucosal blood flow responses to meat extract stimulation in anaesthetized cats. J. Physiol. (Lond.) 253, 493-504 (1975)

15 Yokotani, K., Muramatsu, I. and Fujiwara, M.: Alpha-1 and alpha-2 type adrenoceptors involved in the inhibitory effect of splanchnic nerves on parasympathetically stimulated gastric acid secretion in rats. $J$. Pharmacol. Exp. Ther. 229, 305-310 (1984)

16 Kobinger, $W$. and Pichler, L.: Investigation into different types of post- and presynaptic $\alpha$ adrenoceptors at cardiovascular sites in rats. Eur. J. Pharmacol. 65, 393-402 (1980)

17 Timmermans, P.B.M.W.M. and Van Zweiten, P.A.: Postsynaptic $\alpha_{1}$ and $\alpha_{2}$ adrenoceptors in the circulatory system of the pithed rat: Selective stimulation of the $\alpha_{2}$-type by B-HT 933. Eur. J. Pharmacol. 63, 199-202 (1980)

18 Kobinger, $W$. and Pichler, L.: $\alpha_{1}$ and $\alpha_{2}$-adrenoceptors subtypes: selectivity of various agonists and relative distribution of receptors as determined in rats. Eur. J. Pharmacol. 73, 313321 (1981)

19 Marshall, I., Nasmyth, P.A., Nicholl, C.G. and Shepperson, N.B.: $\alpha$-Adrenoceptors in the mouse vas deferens and their effects on its response to electrical stimulation. Br. J. Phar- macol. 62, 147-151 (1978)

20 Drew, G.M.: Pharmacological characterization of the presynaptic $\alpha$-adrenoceptors regulating cholinergic activity in the guinea-pig ileum. $\mathrm{Br}$. J. Pharmacol. 64, 293-300 (1978)

21 Wikberg, J.: Differentiation between pre- and postjunctional $\alpha$-receptors in guinea pig ileum and rabbit aorta. Acta Physiol. Scand. 103, 225-239 (1978)

22 Lasch, P. and Jakobs, K.H.: Agonistic and antagonistic effects of various $\alpha$-adrenergic agonists in human platelets. Naunyn Schmiedebergs Arch. Pharmacol. 306, 119-125 (1979)

23 Yokotani, K., Muramatsu, I. and Fujiwara, M.: Effects of the sympathetic nervous system on bethanechol-induced elevation of gastric acid secretion and mucosal blood flow in rats. J. Pharmacol. Exp. Ther. 227, 478-483 (1983)

24 Yokotani, K. and Osumi, Y.: Alpha-1 adrenoceptors mediate splanchnic nerve inhibition of pentagastrin-induced gastric acid secretion and mucosal blood flow in rats. J. Pharmacol. Exp. Ther. 236, 743-747 (1986)

25 Yokotani, K. and Osumi, Y.: Lack of direct splanchnic inhibitory effects on histamineinduced gastric acid secretion in rats. J. Pharmacol. Exp. Ther. 236, 770-775 (1986)

26 Jennewein, H.M.: The effect of clonidine on gastric acid secretion in rats and dogs. Naunyn Schmiedebergs Arch. Pharmacol. 297, 85-90 (1977)

27 Cheng, H.C., Gleason, E.M., Nathan, B.A., Lachman, P.J. and Woodward, J.K.: Effects of clonidine on gastric acid secretion in the rat. $J$. Pharmacol. Exp. Ther. 217, 121-126 (1981)

28 Petrash, A.C. and Bylund, D.B.: Alpha-2 adrenoceptor subtypes indicated by $\left[{ }^{3} \mathrm{H}\right]$ yohimbine binding in human brain. Life Sci. 38, 2129 . 2137 (1986)

29 Tsukahara, T., Taniguchi, T., Usui, H., Miwa, S., Shimohama, S., Fujiwara, M. and Handa, H.: Sympathetic denervation and alpha adrenoceptors in dog cerebral arteries. Naunyn Schmiedebergs Arch. Pharmacol. 334, 436-443 (1986) 